\title{
Adolescents motives for selling sex in a welfare state - A Swedish national study
}

Cecilia Fredlund, Örjan Dahlström, Carl Göran Svedin, Marie Wadsby, Linda Jonsson and Gisela Priebe

The self-archived postprint version of this journal article is available at Linköping University Institutional Repository (DiVA):

http://urn.kb.se/resolve?urn=urn:nbn:se:liu:diva-149697

N.B.: When citing this work, cite the original publication.

Fredlund, C., Dahlström, Ö., Svedin, C. G., Wadsby, M., Jonsson, L., Priebe, G., (2018), Adolescents motives for selling sex in a welfare state - A Swedish national study, International Journal of Child Abuse \& Neglect, 81, 286-295. https://doi.org/10.1016/j.chiabu.2018.04.030

Original publication available at:

https://doi.org/10.1016/j.chiabu.2018.04.030

Copyright: Elsevier

http://www.elsevier.com/

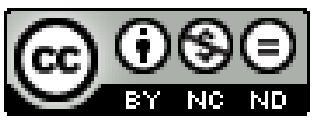




\title{
Adolescents' motives for selling sex in a welfare state - A Swedish national study
}

\author{
Cecilia Fredlund ${ }^{\mathrm{a}}$, Örjan Dahlström ${ }^{\mathrm{b}}$, Carl Göran Svedin ${ }^{\mathrm{c}}$, Marie Wadsby ${ }^{\mathrm{a}}$, \\ Linda S Jonsson ${ }^{c}$, Gisela Priebe ${ }^{\text {cd }}$ \\ ${ }^{a}$ Child and Adolescent Psychiatry, Department of Clinical and Experimental Medicine, Faculty of Medicine, \\ Linköping University, SE-581 85 Linköping, Sweden E-mail: cecilia.fredlund@liu.se, marie.wadsby@liu.se

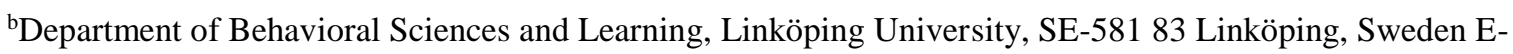 \\ mail: orjan.dahlstrom@liu.se \\ ${ }^{\mathrm{c}}$ Barnafrid, Child and Adolescent Psychiatry, Department of Clinical and Experimental Medicine, Faculty of \\ Medicine, Linköping University, SE-581 83 Linköping, Sweden E-mail: carl.goran.svedin@liu.se, \\ linda.s.jonsson@liu.se \\ ${ }^{\mathrm{d}}$ Department of Psychology, Lund University, SE-22100 Lund Sweden, E-mail: gisela.priebe@ psy.lu.se \\ *Corresponding author: cecilia.fredlund@liu.se, phone: +46 733803063
}




\begin{abstract}
In addition to money or other compensation, other motives for selling sex may be important in a welfare country such as Sweden. The aim of this study was to carry out an exploratory investigation of adolescents' motives for selling sex in a population-based survey in Sweden. A total of 5,839 adolescents from the third year of Swedish high school, mean age 18.0 years, participated in the study. The response rate was $59.7 \%$ and 51 students $(0.9 \%)$ reported having sold sex. Exploratory factor analysis and hierarchical cluster analysis were used to identify groups of adolescents according to underlying motives for selling sex. Further analyses were carried out for characteristics of selling sex and risk factors. Three groups of adolescents were categorized according to their motives for selling sex: Adolescents reporting; 1) Emotional reasons, being at a greater risk of sexual abuse, using sex as a means of self-injury and having a non-heterosexual orientation. 2) Material but no Emotional reasons, who more often receive money as compensation and selling sex to a person over 25 years of age, and 3) Pleasure or no underlying motive for selling sex reported, who were mostly heterosexual males selling sex to a person under 25 years of age, the buyer was not known from the Internet, the reward was seldom money and this group was less exposed to penetrative sexual abuse or using sex as a means of self-injury. In conclusion, adolescents selling sex are a heterogeneous group in regard to underlying motives.
\end{abstract}

Keywords; Selling sex, Adolescent, Child sexual exploitation, Motives, Prostitution 


\section{Introduction}

Population-based studies of adolescents selling sex in the Nordic countries and the United States indicate that more boys than girls sell sex for compensation (Fredlund, Svensson, Svedin, Priebe, \& Wadsby, 2013; McNeal \& Walker, 2016; Mossige, Ainsaar, \& Svedin, 2007; Pedersen \& Hegna, 2003; Svedin \& Priebe, 2007). Selling sex among adolescents has been associated with a few sociodemographic factors including parents' education , economic situation in the family and immigrant background (Fredlund, Svensson, Svedin, Priebe, \& Wadsby, 2013; Lee, Shek, \& Busiol, 2016; Pedersen \& Hegna, 2003; Svedin \& Priebe, 2007), but it has also been associated with sexual, physical and emotional abuse, poor mental health and self-injury (Hwang \& Bedford, 2003; Heilemann \& Santhiveeran, 2011; Lavoie, Thibodeau, \& Gagné, 2010; Svensson, Fredlund, Svedin, Priebe, \& Wadsby, 2013; Svedin \& Priebe, 2007). These findings lead to the following questions: Why do adolescents sell sex in social welfare countries like Sweden? Except for economic reward, are there other motives behind the behavior? Are there any gender differences in the motives for selling sex? Few studies have investigated adolescents' motives for selling sex, and to our knowledge there has been no population-based study of the subject so far.

Buying, but not selling, sexual services is considered a criminal act under Swedish law, but if the person is under 15 years of age it is considered rape (The Swedish Penal Code, Chapter 6). The most common compensation for sexual services among adolescents is money, but other forms of compensation such as drugs, alcohol and cigarettes, food and shelter are also commonly seen (Fredlund, Svensson, Svedin, Priebe, \& Wadsby, 2013; Svedin \& Priebe, 2007; van de Walle, Picavet, van Berlo, \& Verhoeff, 2012). Previous population-based studies indicate that adolescents with experience of selling sex have most commonly sold sex fewer than five times (Fredlund, Svensson, Svedin, Priebe, \& Wadsby, 2013; Lavoie, Thibodeau, \& Gagné, 2010; Svedin \& Priebe, 2007). Interview studies indicate 
that young people who sell sex do not identify themselves with the term 'prostitution', since the selling is often seen as something temporary and the term prostitution is associated with a more long-term or full-time occupation (van de Walle, Picavet, van Berlo, \& Verhoeff, 2012). In this study we use the term 'selling sex' and define it as a form of sexual exploitation of children (see e.g. Hallett 2017).

The prevalence of adolescents selling sex in the Nordic countries has been estimated at $0.6-1.2 \%$ among girls and $1.7-2.1 \%$ among boys, indicating that selling sex is slightly more common among boys than girls (Fredlund, Svensson, Svedin, Priebe, \& Wadsby, 2013; Pedersen \& Hegna, 2003; Svedin \& Priebe, 2007). In a study in the Baltic Sea region which included 18-year-old adolescents in Sweden, Norway, Lithuania, Estonia and Poland, selling sex was more common among boys than girls in all countries except Estonia (Mossige, Ainsaar, \& Svedin, 2007). Studies from the United States have found the prevalence of adolescents who sell sex to be 1-2\% (Kaestle, 2012; McNeal \& Walker, 2016), and more common among boys than girls (McNeal \& Walker, 2016). The prevalence of adolescents who sell sex could however be underestimated in school surveys, since representative studies are hard to perform when dropping out of school is more commonly seen among adolescents selling sex than among those who do not (Brown \& Roe-Sepowiz, 2008; McNeal \& Walker, 2016) and selling sex is negatively associated with feeling happy at school (Kaestle, 2012). In the research concerning adolescents who sell sex, there is currently a strong female gender bias and there are few studies investigating male adolescents selling sex (Mitchell, Moynihan, Pitcher, Francis, English, \& Saewyc, 2017).

In interview studies, the motives for selling sex among adolescents have varied from pure curiosity to being physically forced (Bagley \& Young, 1987; Edinburgh, Pape-Blabolil, Harpin, \& Saewyc, 2015; Hwang \& Bedford, 2004; Song \& Morash, 2014; van de Walle, Picavet, van Berlo, \& Verhoeff, 2012). Differences could especially be seen in the selling of 
sex being perceived by young people as voluntary or forced (Hwang \& Bedford, 2004; van de Walle, Picavet, van Berlo, \& Verhoeff, 2012), even though there might not be a clear line between these two groups, e.g. survival sex could either be defined as voluntary (the person is not physically forced) or forced (the person has no other choice than to sell sex for survival). However, consent is irrelevant and force, fraud or coercion is not required to define minors' selling sex as sexual exploitation according to the UN definition (Miller-Perrin \& Wurtele, 2017). For some individuals, selling sex was perceived as an easy way to get money or expensive gifts or as a way to obtain shelter for the night (Edinburgh, Pape-Blabolil, Harpin, \& Saewyc, 2015; Hwang \& Bedford, 2004; Song \& Morash, 2014; van de Walle, Picavet, van Berlo, \& Verhoeff, 2012). For others, selling sex constituted the main source of income and in general these individuals were found to have more problems with alcohol or drugs, mental health and finances in interview studies (van de Walle, Picavet, van Berlo, \& Verhoeff, 2012). Further motives for selling sex among adolescents were drug abuse (Bagley \& Young, 1987; Hwang \& Bedford, 2004; Kennedy, Klein, Bristowe, Cooper, \& Yuille, 2007), coercion or persuasion by a pimp or boyfriend (Bagley \& Young, 1987; Edinburgh, Pape-Blabolil, Harpin, \& Saewyc, 2015; Kennedy, Klein, Bristowe, Cooper, \& Yuille, 2007; Rothman, Bazzi, \& Bair-Merritt, 2015), influence by senior or junior peers (Bagley \& Young, 1987; Edinburgh, Pape-Blabolil, Harpin, \& Saewyc, 2015; Song \& Morash, 2014), feeling appreciated, being touched or physically close to someone (Hwang \& Bedford, 2004; Jonsson, Svedin, \& Hydén, 2015) or as a way to regulate feelings such as anxiety (Jonsson, Svedin, \& Hydén, 2015). Using sex as a means of self-injury has been strongly associated with selling sex in adolescents (Fredlund, Svedin, Priebe, Jonsson, \& Wadsby, 2017). Interview studies indicate that young heterosexual men have more positive experiences of selling sex while young females have more feelings of shame and guilt after selling sex (van de Walle, Picavet, van Berlo, \& Verhoeff, 2012). 
Selling sex among adolescents is associated with sexual, physical and emotional abuse, poor mental health, self-injury, sexual risk-taking behavior, conduct problems, running away from home, and drug and alcohol abuse (Edinburgh, Pape-Blabolil, Harpin, \& Saewyc, 2015; Edwards, Iritani, \& Hallfors, 2006; Heilemann \& Santhiveeran, 2011; Hwang \& Bedford, 2003; Lavoie, Thibodeau, \& Gagné, 2010; Pedersen \& Hegna, 2003; Svedin \& Priebe, 2007; Svensson, Fredlund, Svedin, Priebe, \& Wadsby, 2013). However, differences have been seen between genders concerning risk factors and adolescents selling sex. For example, mental health problems can be seen especially among girls (Svedin \& Priebe, 2007) and conduct problems and antisocial behavior especially among boys (Pedersen \& Hegna, 2003; Svedin \& Priebe, 2007). Population-based studies indicate that almost all of the girls selling sex have been exposed to sexual abuse while boys have been exposed to a lower extent, about 60-70\%. Penetrative abuse is especially seen among girls (Svedin \& Priebe, 2007; Svensson, Fredlund, Svedin, Priebe, \& Wadsby, 2013). Studies that investigate these factors in relation to motives for selling sex are lacking.

\section{Aim of the study}

The aim of this study was to carry out an explorative investigation of adolescents' motives for selling sex for compensation in a population-based study in Sweden. The study aims were to 1) identify groups of adolescents according to their motives for selling sex, 2) investigate differences in gender concerning motives for selling sex, 3) investigate associations between motives for selling sex and characteristics of selling sex including type of compensation, means of contact with the buyer, number of instances of selling sex and age of the buyer, and 4) investigate associations with risk factors such as trauma symptoms, sexual orientation, sexual abuse, self-injurious behaviors, and alcohol and drug abuse. 


\section{Method}

The questions used for this study were part of a questionnaire used in a national survey in the third year of Swedish high school called 'Young People, Sex and the Internet In a Changing World' that was carried out in the fall of 2014. This survey was partly a replication of two previous surveys from 2004 and 2009 (Svedin \& Priebe, 2004, 2009).

\section{Participants}

The agency Statistics Sweden conducted the selection of study sample, distribution and collection of the questionnaires. A representative national sample from the third year of Swedish high schools, according to size of the school and study program, was selected for the study by using the National School Register from 2013 while the adolescents were in the second year of high school. According to Swedish data from 2014, $91.7 \%$ of all 18-year-old adolescents were enrolled in the Swedish high school system (Statistics Sweden, 2016).

Besides the national sample, an extra sample from Stockholm County, intended for an additional study, was included using the same selection criteria, size of school and study program. The sample from Stockholm County had a lower response rate $(48.7 \%)$ compared to the rest of the country $(65.3 \%)$. The students from Stockholm more often attended medium-sized schools (51.2\% vs $41.6 \%)$. However, the effect size was small $\left(\chi^{2}=63.6, d f=\right.$ $2, p<.001$, Cramer's V = .10). Students from Stockholm also more often followed practical study programs $(33.2 \%$ vs $27.7 \%)$, but the effect size was even smaller $\left(\chi^{2}=17.1, d f=1, p<\right.$ .001 , Cramer's $\mathrm{V}=.05$ ). To increase the sample size of the study, the additional sample from Stockholm County was included in this study. 
Of the 261 schools selected from the National School Register 2013, 171 were still providing the selected programs in the fall of 2014 and agreed to participate in the study with 9,773 eligible participants for the study. In total, 5,873 participants completed the questionnaire. Of these, 34 questionnaires were excluded due to unreliable answers and high amounts of missing data, giving a response rate of $59.7 \%$. The mean age for the participants in the study was 18.0 years $(\mathrm{SD}=0.6)$.

\section{Procedure}

Information about the study was sent by mail to the principal of the selected schools in September 2014 by Statistics Sweden. The students received written information about the study before answering the questionnaire. The students gave informed consent for participation by filling in the questionnaire. In Sweden, active consent is not required from parents of adolescents older than 15 years of age when using questionnaire-based studies (The Ethical Review Act of Sweden, 2003). The study was performed anonymously during lesson time using computers (165 schools) or paper copies (6 schools). With regard to the sensitive topics in the questionnaire, the information letter to the principals of the schools, teachers and participants included contact information for help and support if needed after the participants had answered the questionnaire.

\section{Measures}

Selling sex was measured by using the question 'Have you ever sold sexual services?' with the answer options Yes/No. The question concerning motives for selling sex was formulated as 'What made you sell sexual services? Several answers can be marked' with the following options: a) fun/exciting, b) like to have sex, c) needed money, d) needed 
drugs, e) influenced by peers/partner, f) wanted closeness, g) to feel appreciated, h) did not feel mentally well/to reduce anxiety, i) was affected by alcohol or drugs, j) do not get sex in another way, k) have special sexual desires, l) the buyer persuaded me, m) was forced to sell sex, and n) other (open-ended answer). This question was a modified version of a question used for adults selling sex in an earlier Swedish study (Kuosmanen, 2008).

The characteristics of the selling of sex were measured using the following questions: 'What kind of reimbursement did you receive?', which was analyzed for the alternatives 1) money and 2) material things (merging the three answer options; clothes and jewelry, cellphones and computers, and cellphone refill cards). 'How did you come into contact with the buyer', which was analyzed for the alternative 1) through the Internet (merging three answer options from the questionnaire: through an open chat site, through a community without a focus on sex where I'm a member, and through a dating/sex site). 'How many times have you sold sexual services', with the answer options a) one time b) 2-5 times c) more than 5 times. There was also a question concerning the age of the buyer, including the answer options a) 15-25 years, b) 26-45 years, c) older than 45 years. This question was dichotomized in the analyses as 15-25 years and older than 25 years.

Gender was investigated using the question 'Are you a...' 1) man, 2) woman, and 3) this classification does not fit me. Sexual orientation was analyzed for heterosexual orientation and non-heterosexual orientation including the answer options 1) homosexual, 2) bisexual, 3) queer, 4) unsure, and 5) none of these.

Sexual abuse was investigated using the question 'Have you been exposed to any of the following against your will?', giving the following answer alternatives: 1) someone having exposed himself/herself to you via the Internet or otherwise, 2) someone having touched your genitals/tried to undress you to have sex with you, 3) forced you to masturbate, 
4) vaginal intercourse, 5) oral intercourse, and 6) anal intercourse. Analyses were carried out both for any kind of sexual abuse including the abovementioned answer options and for penetrative sexual abuse including vaginal, oral and anal intercourse.

Nonsuicidal self-injury (NSSI) was investigated using the question 'Have you ever actually engaged in self-injury without the intention of suicide? (That is purposely hurt yourself without wanting to die, e.g. by cutting or burning yourself)', with the answer options Yes/No. This question was included in the structural interview The Self-Injurious Thoughts and Behaviors Interview - Short Form - Self Report (SITBI-SF-SR) that was developed from SITIB (Nock, Holmberg, Photos, \& Michel, 2007). To investigate the use of sex as selfinjury, a new question was formulated for the survey: 'Have you ever used sex to purposely hurt yourself?' with the answer options Yes/No.

The question concerning alcohol binge drinking was formulated as Think of the last 12 months. How often have you, on a single occasion, drunk alcohol comparable to four large cans of strong beer/cider or $25 \mathrm{cl}$ liquor or a bottle of wine or six cans of medium-strength beer?' The answers were analyzed for once a month or more or less than once a month. The question concerning drug abuse was formulated as 'Have you used any of the following?' and included answer options for 1) cannabis, 2) psychostimulants like cocaine or amphetamine, 3) opiates e.g. heroin, 4) Internet drugs like Spice, Mephedrone, MDPV or Kratom, 5) GHB or anabolic steroids, and 6) Ecstasy.

Trauma symptoms were measured using the Trauma Symptom Checklist for Children (TSCC), which comprises 54 items divided into six subscales: anxiety, depression, post-traumatic stress (PTS), dissociation, anger and sexual concerns and an additional subscale with critical items (Briere, 1996). The instrument has been translated into Swedish and validated for the age group 10-17 years old, with Cronbach's alpha .94 for the total scale 
and $0.78-0.83$ for the subscales (Nilsson, Wadsby, \& Svedin, 2008). Cronbach's alpha for the present study was 0.95 for the total scale. For the subscales, Cronbach's alpha was 0.82 for anxiety, 0.88 for depression, 0.87 for PTS, 0.85 for dissociation, 0.84 for anger and 0.65 for sexual concerns.

\section{Data analyses}

The method used, see Figure 1, included exploratory factor analysis with maximum likelihood extraction and oblique rotation (direct oblimin) in order to investigate underlying motives for adolescents to sell sex. The factor analysis included ten motives for selling sex. Three motives were excluded from the factor analysis due to perfect correlation (only one person had answered yes to all three items) and the open-ended answers were also excluded. To decide the number of factors to be retain in the model we used Eigenvalue, scree plot and clinical relevance of the factors. To decide in which group of underlying motives the items belonged, results were interpreted by inspection of the pattern matrix (the unique contribution of each variable to the corresponding factor) and a structure matrix (the total relation between each variable and the corresponding factor), see Table 1 . We also required the division to be clinically relevant. This resulted in three underlying motives for selling sex.

Since participants had the possibility to report several motives for selling sex, there were eight possible combinations of response patterns for the three underlying motives identified in the factor analysis. Hierarchical cluster analysis was used as support to identify groups of adolescents according to their response patterns for the three underlying motives, see Figure 1. The cluster analysis resulted in four groups of adolescents. Two of these groups had similar patterns of risk factors and were combined in the final analysis. The final three groups of adolescents were analyzed for gender, characteristics for the selling of sex and risk 
factors including sexual abuse, self-injury, sexual orientation, alcohol binge drinking and drug abuse by using Chi-square test and Fisher's exact test. TSCC scores were analyzed by using Independent samples $t$-test. For these analyses one group was compared with the other two groups combined. Percentages in the tables are related to the number of adolescents who answered the question and the internal loss is indicated at the top of the tables. As references in the tables for risk factors we used the total number of adolescents selling sex compared to adolescents not selling sex. All statistical analyses were carried out in Statistical Package of the Social Sciences (SPSS) version 23.

\section{Ethical approval}

The Regional Ethical Review Board of Linköping University, Sweden (Dnr 131-31) ethically approved this study.

\section{Results}

Of the 5,764 participants, $51(0.9 \%)$ stated that they had sold sex for compensation on any one occasion. Of these, $31(60.8 \%)$ were male, $18(35.3 \%)$ female and $2(3.9 \%)$ did not find the classification as male or female appropriate for them.

Underlying motives for selling sex-factor analysis

To find the underlying motives for adolescents to sell sex, exploratory factor analysis was used, see Table 1. The scree plot suggested a two-factor model. However, four factors had an Eigenvalue over 1 which is why two-, three- and four-factor models were tried and the three-factor solution was found to be most clinical relevant. 
Table 1 shows the three underlying motives for selling sex: Factor 1 - Emotional reasons including the options 'Wanted closeness', 'To feel appreciated', 'Did not feel mentally well/To reduce anxiety' and 'The buyer persuaded me'. This was the first and most important factor, explaining $32 \%$ of the variance. Factor 2 - Material reasons including the options 'Needed money' and 'Needed drugs'. As seen in Table 1, the item 'Needed money' was loading on both Factor 2 and Factor 3 in the Pattern matrix and had a quite equal loading for Factor 2 and Factor 3 in the Structure matrix. However, we found it more clinically relevant to keep it in the Factor 2 group. Factor 2 explained $17 \%$ of the variance. Factor 3 Pleasure, including the motives 'Fun/exciting', 'Like to have sex', 'Influenced by peers/partners', and 'Affected by alcohol or drugs', explained $11 \%$ of the variance. The Kaiser-Meyer-Olkin value was .59, which indicated a fairly low sample size.

Ten adolescents did not report any of the three underlying motives for selling sex, but five of these had given reasons for selling sex in the open-ended answers including 'needed a place to sleep and a lift', 'wanted cigarettes' or 'soft drinks'. No differences were seen between gender and motives for selling sex, see Table 2.

Motives for selling sex-Cluster analysis

Since participants had the possibility to report several motives for selling sex, hierarchical cluster analysis was used as support to identify groups of adolescents according to their response patterns of the three underlying motives Emotional reasons, Material reasons and Pleasure. If a person had responded yes to an underlying motive for selling sex he/she was classified as 1 , otherwise 0 , giving eight possible combination of answer patterns: 1) Emotional reasons only, 2) Emotional reasons and Pleasure, no Material reasons, 3) Emotional and Material reasons, no Pleasure, 4) Material reasons only, 5) Material reasons 
and Pleasure, no Emotional reasons, 6) Pleasure only, 7) all three factors, and 8) no factor. No person reported factor 3) Emotional and Material reasons, no Pleasure. According to the cluster analysis these eight groups were divided into four cluster groups: 1) adolescents reporting Emotional reasons and yes/no to Pleasure, 2) adolescents reporting Material reasons and yes/no to Enhancement, 3) adolescents reporting Pleasure only or no underlying reason, and 4) adolescents reporting all three underlying motives. However, cluster groups 1 and 4 were found to have similar patterns of risk factors which was concordant with our clinical theory that adolescents with Emotional reasons could be grouped regardless of whether or not they report other kinds of motives for selling sex. This resulted in the three groups of adolescents selling sex: 1) Emotional reasons with or without other reasons, 2) Material reasons with or without Pleasure but no Emotional reasons, and 3) Pleasure only or no underlying motive for selling sex.

Motives for selling sex and gender, characteristics of selling sex and risk factors

As seen in Table 3, Adolescents with Emotional reasons for selling sex were found to have an almost equal distribution of male (52.6\%) and female (42.1\%) adolescents. The most common compensation received was money (47.4\%), but compared to the other adolescents selling sex they had more often received material things as compensation $(36.8 \%$, Fisher's Exact Test, $p=.030$ ). For this group, the most common way to get in contact with the buyer was through the Internet (57.9\%) and the buyers were most commonly someone over 25 years of age $(73.7 \%)$. The selling had often occurred more than five times $(42.1 \%)$. As seen in Table 4, compared to all other adolescents selling sex, adolescents with Emotional reasons had more often been exposed to sexual abuse $\left(82.4 \%, \chi^{2}=4.0, d f=1, p=.047\right)$, they used sex as a means of self-injury more often $\left(52.6 \%, \chi^{2}=9.6, d f=1, p=.002\right)$ and 
heterosexual orientation was more unusual $\left(42.1 \%, \chi^{2}=4.4, d f=1, p=.035\right)$. Exposure to penetrative sexual abuse was common (47.4\%) as well as nonsuicidal self-injury (52.6\%).

Adolescents with Material but no Emotional reasons for selling sex were found to have an equal distribution of male (41.7\%) and female (50.0\%) adolescents, as seen in Table 3. This group received money as compensation more often $\left(91.7 \%, \chi^{2}=15.1 d f=1, p<\right.$ .001) compared to other adolescents selling sex and the buyers were more often over 25 years of age $\left(83.3 \%, \chi^{2}=4.5, d f=1, p=.034\right)$. The most common way to get in contact with the buyer was through the Internet (63.6\%) and most of the adolescents had sold sex more than once $(91.7 \%)$. As seen in Table 4, sexual abuse was common (58.3\%) including penetrative sexual abuse (58.3\%). Nonsuicidal self-injury was common $(41.7 \%)$ in this group but not using sex as a means of self-injury (16.7\%). Heterosexual orientation was relatively uncommon in the group (50\%).

As seen in Table 3, compared to other adolescents selling sex, adolescents with Pleasure only or no underlying motive for selling sex were more often male (80\%) and not female $\left(20 \%, \chi^{2}=4.1, d f=1, p=.044\right)$. This group had to a lesser extent received money as compensation $\left(10 \%, \chi^{2}=14.7, d f=1, p<.001\right)$, they used the Internet as a means of contact with the buyer to a lesser extent $\left(25 \%, \chi^{2}=5.9, d f=1, p=.015\right)$ and the buyer was usually not over 25 years of age $\left(25 \%, \chi^{2}=13.6, d f=1, p<.001\right)$. For this group it was common to have sold sex only once (52.9\%). As seen in Table 4, adolescents with Pleasure only or no underlying motive for selling sex had to a lesser extent been exposed to penetrative sexual abuse $\left(20.0 \%, \chi^{2}=5.1, d f=1, p=.024\right)$, they used sex as a means of self-injury to a lesser extent $\left(10.0 \%, \chi^{2}=5.0, d f=1, p=.025\right)$ and heterosexual orientation was more common $\left(85.0 \%, \chi^{2}=8.1, d f=1, p=.004\right)$ compared to other adolescents selling sex. However, many had been exposed to sexual abuse (47.4\%) and nonsuicidal self-injury was found in the group $(25.0 \%)$ 
In terms of alcohol binge drinking, drug abuse and trauma symptoms, no differences were seen between the groups divided up according to motives for selling sex. Overall, however, all adolescents selling sex had more trauma symptoms, alcohol binge drinking and drug abuse compared to adolescents not selling sex.

\section{Discussion}

Our understanding of why adolescents sell sex in social welfare countries like Sweden is limited. To our knowledge, there are no earlier population-based studies investigating adolescents' motives for selling sex. The current study is also an important study when trying to understand gender differences found in earlier population-based studies indicating that more boys than girls sell sex (Fredlund, Svensson, Svedin, Priebe, \& Wadsby, 2013; McNeal \& Walker, 2015; Mossige, Ainsaar, \& Svedin, 2007; Pedersen \& Hegna, 2003; Svedin \& Priebe, 2007). This study indicates that adolescents selling sex are a heterogeneous group in regard to motives for selling sex which is concordant with earlier interview studies (Edinburgh, Pape-Blabolil, Harpin, \& Saewyc, 2015; Jonsson, Svedin, \& Hydén, 2015; Kennedy, Klein, Bristowe, Cooper, \& Yuille, 2007; van de Walle, Picavet, van Berlo, \& Verhoeff, 2012). However, we also found differences in risk factors and the characteristics of the selling of sex in relation to underlying motives for selling sex. In our study we identified three groups of adolescents according to their underlying motives for selling sex.

First, Emotional reasons were found to be important reasons for adolescents to sell sex in Sweden. Emotional reasons included the motives 'wanted closeness', 'to feel appreciated', 'did not feel mentally well/to reduce anxiety' and 'the buyer persuaded me'. Emotional reasons were significantly associated with sexual abuse, using sex as a means of self-injury and non-heterosexual orientation. As has been described in interview studies, the 
reward seems to be less important for this group and instead the selling of sex serves other functions such as coping with emotional needs and validation (Hwang \& Bedford, 2004; Jonsson, Svedin, \& Hydén, 2015). Using sex as a means of self-injury (SASI) is a behavior that has been highlighted in Sweden in recent years. It has been associated with selling sex, previous sexual abuse, especially penetrative sexual abuse, non-heterosexual orientation, trauma symptoms, nonsuicidal self-injury (NSSI) like cutting or burning the skin and health care for suicide attempts, depression and eating disorders (Fredlund, Svedin, Priebe, Jonsson, \& Wadsby, 2017). SASI has been found to serve the same functions as NSSI with automatic functions such as 'to relive feeling numb or empty', 'to stop bad feelings' or 'to punish oneself' being the most commonly endorsed, but SASI has been more associated with social influence compared to NSSI (Jonsson, Svedin, Priebe, Fredlund, Wadsby, \& Zetterqvist, 2017). In interview studies, the selling of sex for emotional needs has been described as searching for sexual encounters (the selling of sex) to reduce feelings like anxiety, relief for anxiety during the sexual encounter but resulting in more anxiety afterwards, resulting in a vicious cycle (Jonsson, Svedin, \& Hyden, 2015). The aspects of poor mental health associated with selling sex for emotional reasons are important for professionals to be aware of. In regard to support and treatment, it is important to provide trauma-informed care as well as trauma-focused treatment (Bath, 2008; Cohen, Mannarino, \& Deblinger, 2006). In regard of the similarities of functions between NSSI and SASI, treatment also needs to focus on affect regulations skills including social skills for receiving human attention and strengthening relationships (Jonsson, Svedin, Priebe, Fredlund, Wadsby, \& Zetterqvist, 2017). According to our study, emotional reasons are one of the most important motives for selling sex in a welfare country such as Sweden. This may not be the case in a less prosperous country were material reasons might be more important. However, this needs to be investigated in further studies. 
Second, for adolescents with material but no emotional reasons for selling sex the reward seems to be important (money or drugs). For this group the buyer is more often older than 25 years and the Internet is more often used as means of contact. To give proper help and support for this group, it is probably necessary to give support for drug addiction or to take into account what the money is needed for. Does the person have social problems? Did he/she run away from home? Does the selling of sex constitute the main source of income or is it seen as an easy way of receiving money (Hwang \& Bedford, 2004; Song \& Morash, 2014; van de Walle, Picavet, van Berlo, \& Verhoeff, 2012)? This group is important to take into account since it might be a risk group for later adult prostitution.

Third, motives for selling sex in the group of adolescents with Pleasure were: 'fun/exciting', 'like to have sex', 'influenced by peers/partners' or 'affected by alcohol or drugs'. This group also included ten adolescents who did not give any reason why they had sold sex or who gave an open-ended answer. This group indicates that there are adolescents selling sex for pleasure and fun but these adolescents are usually not selling sex on a regular basis $-50 \%$ had sold sex only once. This group could be the group described in interviews as finding the situation of selling sex as exciting, finding the partner attractive, and the reward being just one aspect of the motives for selling sex (van de Walle, Picavet, van Berlo, \& Verhoeff, 2012). It is possible that this group sells sex more as a way to explore sexual limitations. The group was mainly composed of heterosexual boys selling sex to someone younger than 25 years of age, and in comparison to the other two groups they used the Internet as a means of contact with the buyer to a lesser extent. This might indicate that the buyer was someone in the same age group and probably someone that the person knew. In interview studies, heterosexual males have been found to report more positive feelings in regard to selling sex compared to females who report more feelings of shame and guilt (van de Walle, Picavet, van Berlo, \& Verhoeff, 2012). However, in these kinds of studies it has to 
be taken into account that boys might be expected to find all kinds of sexual situations more exciting than females because of gender roles, which also might affect the findings of our study. It has to be kept in mind that it is always a form of sexual exploitation if the person is a minor regardless of the motive for selling sex (Miller-Perrin \& Wurtele, 2017). Compared to the other two groups, this study indicates that adolescents with pleasure or no underlying motive for selling sex were less exposed to penetrative sexual abuse and using sex as a means of self-injury to a lower extent, indicating a less burdened group. However, compared with all other adolescents in the third year of Swedish high school, adolescents with experience of selling sex were more burdened in regard to all risk factors.

\section{Limitations}

A limitation of the study is the small index group. The KMO value for the factor analysis indicates that the sample is small but acceptable and the group is also small for the cluster analysis. For this reason we do not have a stable model, but we have achieved a first attempt at understanding the motives behind selling sex among adolescents in a welfare country like Sweden. We are however planning a new epidemiologic study including the same questions with the possibility to confirm or modify the model.

Another limitation of the study is the response rate. About $40 \%$ of the adolescents who had the possibility to participate in the study did not do so. We know that adolescents selling sex are at risk of dropping out of school (Brown \& Roe-Sepowiz, 2008; McNeal \& Walker, 2016) and selling sex among adolescents is negatively associated with feeling happy at school (Kaestle, 2012). For this study, this means that the sample answering the questionnaire might not be fully representative of adolescents selling sex even though the sample should be representative of adolescents in the third year of Swedish high school in 
terms of gender, school size and study program. Further, about $8 \%$ of Swedish 18 -year-old do not attend high school at all according to Swedish data from 2014 (Statistics Sweden, 2016). It is possible that the prevalence of selling sex might be even higher in the group of adolescents that are absent or not attending school and it is also possible that the motives for selling sex differ for these adolescents. For example, only one person reported having been forced to sell sex and nine had been persuaded to sell sex, and this finding might be underestimated in the present study due to the study design.

Recall bias is always a limitation in questionnaire-based studies, as is the question of whether the answers are trustworthy. Before analysis, all answers were reviewed for trustworthiness and 34 questionnaires were excluded due to unserious answers (not all of these claimed to have sold sexual services). This means that the answers left in the study are considered trustworthy.

\section{Conclusions}

This study is based on a small study group, but it is still an important study for trying to understand motives for adolescents selling sex in a social welfare country like Sweden. The study indicates that adolescents selling sex are a heterogeneous group with different underlying motives associated with different kinds of risks. Emotional reasons as underlying motives for selling sex are important reasons for selling sex in Sweden, and these reasons are associated with sexual abuse, non-heterosexual orientation and using sex as a means of selfinjury. There is also a group of adolescents selling sex for pleasure and fun, mostly composed of heterosexual males. This group could be adolescents using selling sex as a way to explore sexual limitations. However, adolescents selling sex as a group are more exposed to all kinds of risk factors compared to their peers, even if differences are seen between the groups of 
different motives. When giving help and support to adolescents selling sex, it is important to take into account the underlying motives since a person with Emotional reasons for selling sex might have different needs for support than a person selling for money or drugs, or for pleasure and fun.

\section{Acknowledgements}

The study was funded by the Ministry of Health and Social Affairs/the Children's Welfare Foundation Sweden and the County of Stockholm, Sweden. The authors report no conflicts of interest. 


\section{References}

Bagley, C. \& Young L. (1987). Juvenile prostitution and child sexual abuse: A controlled study. Canadian Journal of Community Mental Health, 6, 5-26.

Bath, H. (2008). The Three Pillars of Trauma- Informed Care. Reclaiming Children and Youth, 17. 17-21.

Briere, J. (1996) Trauma Symptom Checklist for Children (TSCC) Professional Manual.

Odessa, FL: Psychological Assessment Resource.

Brown, K.M., \& Roe-Sepowitz, D. (2008). Female juvenile prostitutes: Exploring the relationship to substance use. Child and Youth Services Review, 30, 1395-1402. doi:10.1016/j.childyouth.2008.04.011

Cohen, J.A., Mannarino, A.P., \& Deblinger, E. (2006). Treating Trauma and Traumatic Grief in Children and Adolescents. New York: The Guilford Press.

Edinburgh, L., Pape-Blabolil, J., Harpin, S.B., \& Saewyc, E. (2015). Assessing experience of girls and boys seen at a Child Advocacy Center. Child Abuse and Neglect, 46, 47-59. doi:10.1016/j.chiabu.2015.04.016

Edwards J.M., Iritani B.J., \& Hallfors D.D. (2006). Prevalence and correlates of exchanging sex for drugs and money among adolescents in the United States. Sexually Transmitted Infections, 82, 354-358. doi:10.1136/sti.2006.020693

The Ethical Review Act (2003) The Act Concerning The Ethical Review Of Research Involving Humans (SFS 2003:460). Stockholm: The Swedish Ministry of Education and Cultural Affairs: Stockholm.

Fredlund, C., Svensson, F., Svedin, C.G., Priebe, G., \& Wadsby, M. (2013). Adolescents' lifetime experience of selling sex: Development over five years. 
Journal of Child Sexual Abuse, 22, 312-325.

doi:10.1080/10538712.2013.743950

Fredlund, C., Svedin, C.G., Priebe, G., Jonsson, L., \& Wadsby, M. (2017). Self-reported frequency of sex as self-injury (SASI) in a national study of Swedish adolescents and association to sociodemographic factors, sexual behaviors, abuse and mental health. Journal of Child and Adolescents Mental Health, 11:9. doi:10.1186/s13034-017-0146-7

Government Offices of Sweden. The Swedish Penal Code, Chapter 6. Ministry of Justice; 1962. 2014. Available at http://www.government.se/governmentpolicy/judicial-system/chapter-6-of-the-swedish-penal-code/ 23 August 2016.

Hallet, S. (2017). Making Sense of Child Sexual Exploitation. Exchange, Abuse and Young People. Policy Press; Bristol, UK. ISBN 978-1447333609

Heilemann, T. \& Santhiveeran J. (2011). How do female adolescents cope and survive the hardships of prostitution? A content analysis of existing literature. Journal of Ethic \& Cultural Diversity in Social Work, 20, 57-76. doi:10.1080/15313204.2011.545945

Hwang, S.-L. \& Bedford, O. (2004). Juveniles' motivation for remaining in prostitution. Psychology of Women Quarterly, 28, 136-146. doi:10.1111/j.14716402.2004.00130.x

Hwang, S.-L., \& Bedford, O. (2003). Precursors and pathways to adolescent prostitution in Taiwan. The Journal of Sex Research, 40, 201-210.

doi:10.1080/00224490309552181 
Jonsson, L.S., Svedin, C.G., \& Hydén, M. (2015). Young women selling sex online narratives on regulating feelings. Adolescents Health, Medicine and Therapeutics, 6, 1-11. doi:10.2147/AHMT.S77324

Jonsson, L.S., Svedin, C.G., Priebe, G., Fredlund, C., Wadsby, M., \& Zetterqvist M. (2017). Similarities and differences in the functions of nonsuicidal self-injury (NSSI) and sex as self-injury (SASI). Suicidal and Life-Threatening Behavior, (in press) doi:10.1111/sltb.12417

Kaestle, C.E. (2012). Selling and buying sex: a longitudinal study of risk and protective factors in adolescence. Prevention Science, 13, 314-322. doi:10.1007/s11121011-0268-8

Kennedy, M.A., Klein, C., Bristowe, J.T.K., Cooper, B.S., \& Yuile, J.C. (2007). Routes of recruitment. Journal of Aggression, Maltreatment \& Trauma, 15, 1-19. doi:10.1300/J146v15n02_01

Kuosmanen, J. (2008). Tio år med lagen: Om förhållningssätt till och erfarenheter av prostitution i Sverige. [Ten years with the law: About approaches to and experiences of prostitution in Sweden]. In C. Holmström, M.L., Skilbrei (Eds.), Prostitution i Norden [Prostitution in the Nordic Region]. (pp. 357 - 381). TemaNord 2008:604. Copenhagen: The Nordic Council of Ministers.

Lavoie, L., Thibodeau, C., Gagné, M.H., \& Hébert, M. (2010). Buying and selling sex in Québec adolescents: a study of risk and protective factors. Archives of Sexual Behavior, 39, 1147-1160. doi:10.1007/s10508-010-9605-4

Lee, T. Y., Shek, D. T. L., \& Busiol, D. (2016). A longitudinal study of compensated dating and juvenile prostitution behaviors among adolescents in Hong Kong. 
Journal of Pediatric and Adolescent Gynecology, 29, 31-37.

doi:10.1016/j.jpag.2015.10.006

McNeal, B.A. \& Walker, J.T. (2016). Parental effects on the exchange of sex for drugs or money in adolescents. American Journal of Criminal Justice, 41, 710-731. doi:10.1007/s12103-015-9313-7

Miller-Perrin, C. \& Wurtele, S.K. (2017). Sex trafficking and the commercial sexual exploitation of children. Women \& Therapy, 40, 123-151. doi:10.1080/02703149.2016.1210963

Mitchell, K., Moynihan, M., Pitcher, C., Francis, A., English, A., \& Saewyc, E. (2017). Rethinking research on sexual exploitation of boys: Methodological challenges and recommendations to optimize future knowledge generation. Child Abuse \& Neglect, 66, 142-151. doi:10.1016/j.chiabu.2017.01.019

Mossige, S., Ainsaar, M., \& Svedin, C. G. (Eds.). (2007). The Baltic Sea regional study on adolescents' sexuality (NOVA Report 18/07) (pp 33-39). Oslo, Norway: Norwegian Social Research.

Nilsson, D., Wadsby, M., \& Svedin, C.G. (2008). The psychometric properties of the Trauma Symptom Checklist for Children (TSCC) in a sample of Swedish children. Child Abuse \& Neglect, 32, 627-636.

doi:10.1016/j.chiabu.2007.09.009

Nock, M.K., Holmberg, E.B., Photos, V.I., \& Michel, B.D. (2007). Self-injurious thought and behaviors interview: development, reliability and validity in an adolescent sample. Psychological Assessment, 19, 309-317. doi:10.1037/10403590.19.3.309. 
Pedersen, W. \& Hegna, K. (2003). Children and adolescents who sell sex: a community study. Social Science \& Medicine, 56, 135-147. doi:10.1016/S02779536(02)00015-1

Rothman, E.F., Bazzi, A.R., \& Bair-Merritt, M. (2015). 'I'll do whatever as long as you keep telling me that I'm important": A case study illustrating the link between adolescent dating violence and sex trafficking victimization. Journal of Applied Research on Children, 6.

Song, J. \& Morash, M. (2014). Materialistic desires or childhood adversities as explanations for girls' trading sex for benefits. International Journal of Offender Therapy and Comparative Criminology, 60, 62-88.

doi:10.1177/0306624X14543769

Statistics Sweden. (2016). Sweden, Stockholm. http://www.statistikdatabasen.scb.se Accessed 24 August 2016.

Svedin, C.G. \& Priebe, G. (2004). Ungdomars sexualitet - attityder och erfarenheter. Avsnitt: sexuell exploatering. Att sälja sex mot ersättning/pengar [Young people's sexuality - attitudes and experiences. Section: Sexual exploitation. Selling sex for remuneration/money]. In Statens offentliga utredningar, Sexuell exploatering av barn i Sverige [Sexual exploitation of children in Sweden] (pp. 265-357). SOU 2004:71. Stockholm: The Government Offices of Sweden.

Svedin, C.G. \& Priebe, G. (2007). Selling sex in a population-based study of high school seniors in Sweden: Demographic and psychosocial correlates. Achieves of Sexual Abuse, 36, 21-32. doi:10.1007/s10508-006-9083-x

Svedin, C.G. \& Priebe, G. (2009). Unga, sex och Internet [Young people, sex and the Internet]. In Ungdomsstyrelsen, Se mig - unga om sex och Internet [See me- 
Young people on sex and the Internet] (pp.33-148). Stockholm: The Swedish Agency for Youth and Civil Society.

Svensson, F., Fredlund, C., Svedin, C.G., Priebe, G., \& Wadsby, M. (2013). Adolescents selling sex: exposure to abuse, mental health, self-harm behavior and the need of help and support - a study of a Swedish national sample. Nordic Journal of Psychiatry, 67, 81-88. doi:10.3109/08039488.2012.679968

van de Walle R, Picavet C, van Berlo W, \& Verhoeff A. (2012). Young Dutch People's Experiences of Trading Sex: A Qualitative Study. The Journal of Sex Research, 49, 547-557. doi:10.1080/00224499.2011.618955 
Factor analysis identify underlying motives for selling sex

Cluster analysis - identify groups of adolescents according to underlying motives for selling sex

\section{Comparison between groups according to motives for selling sex}

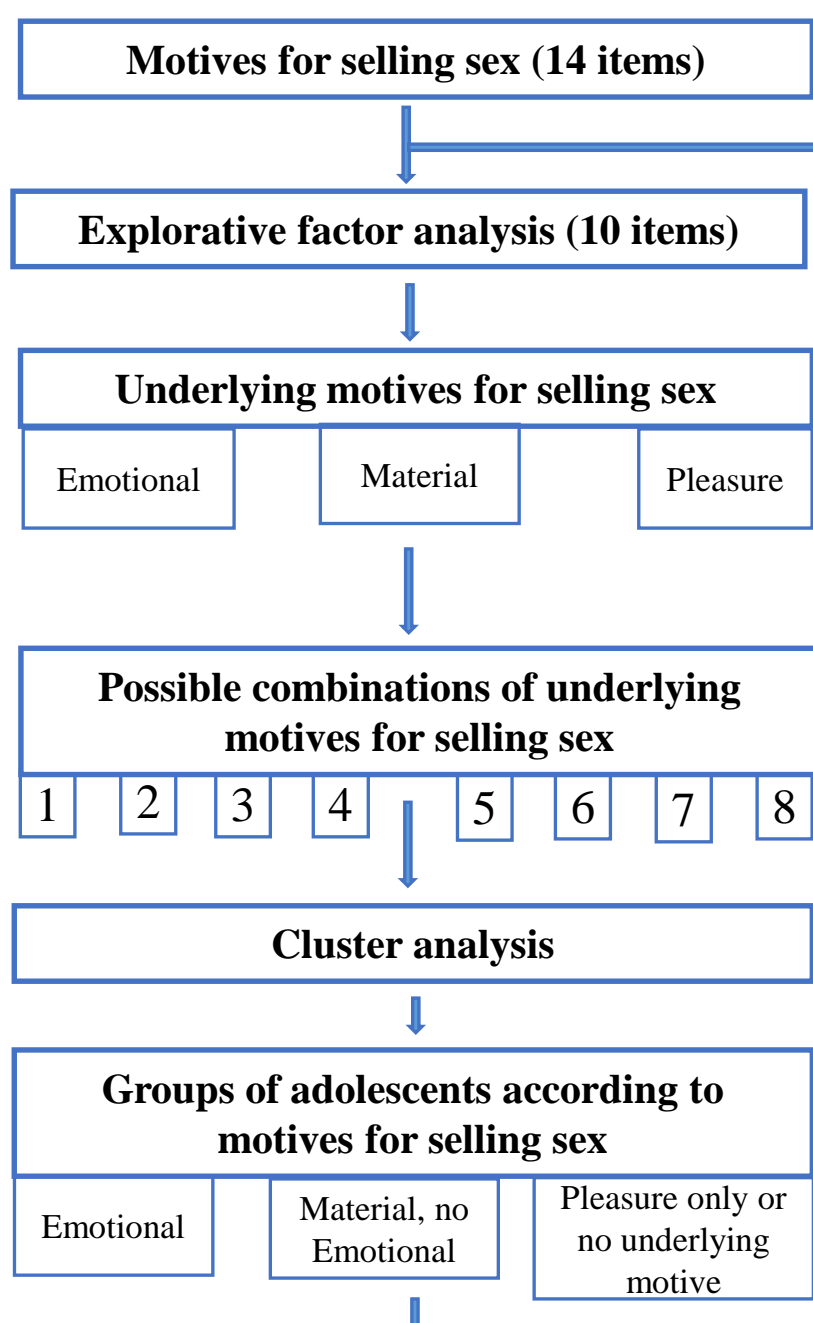

Analysis of gender, characteristics of selling sex and risk factors using $\mathrm{Chi}^{2}$ test, Fisher's Exact Test and Independent T-test 
Table 1

Exploratory factor analysis with maximum likelihood extraction and oblique rotation (direct oblimin) with ten motives for selling sex. Pattern matrix $(P)$ and Structure matrix (S) using a cut off at .20. KMO .59.

\begin{tabular}{|l|c|c|c|}
\hline & Factor 1 & Factor 2 & Factor 3 \\
\cline { 2 - 4 } & $\begin{array}{c}\text { Emotional } \\
\text { reasons }\end{array}$ & $\begin{array}{c}\text { Material } \\
\text { reasons }\end{array}$ & Pleasure \\
\hline Fun/exciting & $\mathbf{P}(\mathrm{S})$ & $\mathbf{P}(\mathrm{S})$ & $\mathbf{P}(\mathrm{S})$ \\
Like to have sex & $(.28)$ & & $\mathbf{. 6 4}(.65)$ \\
Influenced by peers/partner & $(.23)$ & $\mathbf{. 7 0}(.65)$ \\
Affected by alcohol or drugs & $(.23)$ & $\mathbf{. 2 0}(.29)$ & $\mathbf{. 4 9}(.53)$ \\
Needed money & & $.24(.34)$ & $\mathbf{. 4 5}(.48)$ \\
Needed drugs & $\mathbf{. 9 8}(.996)$ & $(.31)$ \\
Wanted closeness & $\mathbf{. 7 5}(.76)$ & & $(.31)$ \\
To feel appreciated & $\mathbf{. 9 3}(.98)$ & & $(.46)$ \\
Did not feel mentally well/ & $\mathbf{. 8 1}(.81)$ & & $(.30)$ \\
To reduce anxiety & & & \\
The buyer persuaded me & $\mathbf{5 0}(.49)$ & & 1.08 \\
\hline $\begin{array}{l}\text { Eigenvalues } \\
\text { \% of variance }\end{array}$ & 3.23 & 1.74 & 10.84 \\
\hline
\end{tabular}

Note: Three answer options were excluded from the factor analysis ('Do not get sex in another way', 'Have special sexual desires', 'Was forced to sell sex') since only one and the same person had answered yes to all three items. The answer option 'Other' (open-ended answer) was also excluded. 
Table 2

Motives for selling sex and gender using Chi-square test and Fisher's Exact Test.

\begin{tabular}{|c|c|c|c|c|}
\hline \multirow{3}{*}{$\begin{array}{l}\text { What made you sell } \\
\text { sexual services? Several } \\
\text { answers could be marked }\end{array}$} & Male & Female & & \multirow[b]{3}{*}{$\mathrm{p}$-value } \\
\hline & $n=31$ & $n=18$ & & \\
\hline & $\%(n)$ & $\%(n)$ & $\mathrm{df}$ & \\
\hline Pleasure & $61.3(19)$ & $55.6(10)$ & 1 & $n s$ \\
\hline Fun/exiting & $45.2(14)$ & $33.3(6)$ & 1 & $n s$ \\
\hline Like to have sex & $51.6(16)$ & $27.8(5)$ & 1 & $n s$ \\
\hline $\begin{array}{l}\text { Influenced by } \\
\text { peers/partner }\end{array}$ & 9.7 (3) & $11.1(2)$ & 1 & ns \\
\hline $\begin{array}{l}\text { Was affected by } \\
\text { alcohol or drugs }\end{array}$ & $12.9(4)$ & $11.1(2)$ & 1 & $n s$ \\
\hline Material reasons & $29.0(9)$ & $50.0(9)$ & 1 & $n s$ \\
\hline Needed money & $25.8(8)$ & $50.0(9)$ & 1 & $n s$ \\
\hline Needed drugs & 9.7 (3) & $16.7(3)$ & 1 & $n s$ \\
\hline Emotional reasons & $32.3(10)$ & $44.4(8)$ & 1 & $n s$ \\
\hline Wanted closeness & $9.7(3)$ & $22.2(4)$ & 1 & $n s$ \\
\hline To feel appreciated & $16.1(5)$ & $27.8(5)$ & 1 & $n s$ \\
\hline $\begin{array}{l}\text { Did not feel mentally } \\
\text { well/to reduce anxiety }\end{array}$ & $22.6(7)$ & $44.4(8)$ & 1 & $n s$ \\
\hline The buyer persuaded me & $19.4(6)$ & $16.7(3)$ & 1 & $n s$ \\
\hline Other/no answer & $25.8(8)$ & $11.1(2)$ & 1 & $n s$ \\
\hline
\end{tabular}


Table 3

Motives for selling sex, gender and characteristics for selling sex. Each group compared with the other two groups combined using Chi-square test and Fisher's Exact Test. The total number of adolescents selling sex is presented as reference.

\begin{tabular}{|c|c|c|c|c|}
\hline & $\begin{array}{c}\text { Emotional } \\
\text { reasons }\end{array}$ & $\begin{array}{c}\text { Material but no } \\
\text { Emotional reasons }\end{array}$ & $\begin{array}{l}\text { Pleasure only or no } \\
\text { underlying motive }\end{array}$ & $\begin{array}{c}\text { Total } \\
\text { selling sex }\end{array}$ \\
\hline & $\begin{array}{l}n=19 \\
\%(n)\end{array}$ & $\begin{array}{c}n=11-12 \\
\%(n)\end{array}$ & $\begin{array}{c}n=17-20 \\
\%(n)\end{array}$ & $\begin{array}{c}n=48-51 \\
\%(n)\end{array}$ \\
\hline Total no. selling sex & $37.3(19)$ & $23.5(12)$ & $39.2(20)$ & $100(51)$ \\
\hline Gender & & & & \\
\hline Male & $52.6(10)$ & $41.7(5)$ & $80.0(16)^{*}$ & $60.8(31)$ \\
\hline Female & $42.1(8)$ & $50.0(6)$ & $20.0(4)^{*}$ & $35.3(18)$ \\
\hline $\begin{array}{l}\text { The classification of male or } \\
\text { female does not fit } \\
\text { Kind of compensation }\end{array}$ & $5.3(1)$ & $8.3(1)$ & $0(0)$ & $3.9(2)$ \\
\hline Money & $47.4(9)$ & $91.7(11)^{* * *}$ & $10.0(2)^{* * *}$ & $43.1(22)$ \\
\hline Material things & $36.8(7) *$ & $9.1(1)$ & $10.0(2)$ & $20.0(10)$ \\
\hline Means of contact with the buyer & & & & \\
\hline $\begin{array}{l}\text { The Internet } \\
\text { Age of the buyer }\end{array}$ & $57.9(11)$ & $63.6(7)$ & $25.0(5)^{*}$ & $46.0(23)$ \\
\hline $\begin{array}{l}\text { Buyer }>25 \text { years of age } \\
\text { Times selling sex }\end{array}$ & $73.7(14)$ & $83.3(10)^{*}$ & $25.0(5)^{* * *}$ & $56.9(29)$ \\
\hline 1 time & $31.6(6)$ & $8.3(1)$ & $52.9(9)$ & $33.3(16)$ \\
\hline 2-5 times & $26.3(5)$ & $66.7(8)$ & $29.4(5)$ & $37.5(18)$ \\
\hline$>5$ times & $42.1(8)$ & $25.0(3)$ & $17.6(3)$ & $29.2(14)$ \\
\hline
\end{tabular}

Note. ${ }^{*} p \leq .05 * * p \leq .01 * * * p \leq .001$ 


\section{Table 4}

Motives for selling sex and risk factors including sexual abuse, self-injury, sexual orientation, alcohol binge drinking, drug abuse and trauma symptoms measured by Trauma Symptom Checklist for Children (TSCC). Each group compared with the other two groups combined using Chi-square test, Fishers Exact Test and Independent t-test. The total group of adolescents selling sex is compared with adolescents not selling sex as reference.

\begin{tabular}{|c|c|c|c|c|c|}
\hline & $\begin{array}{l}\text { Emotional } \\
\text { reasons }\end{array}$ & $\begin{array}{l}\text { Material but no Emotional } \\
\text { reasons }\end{array}$ & $\begin{array}{l}\text { Pleasure only or no } \\
\text { underlying motive }\end{array}$ & Total selling sex & Not selling sex \\
\hline & $\begin{array}{c}n=17-19 \\
\%(n)\end{array}$ & $\begin{array}{c}n=11-12 \\
\%(n)\end{array}$ & $\begin{array}{c}n=19-20 \\
\%(n)\end{array}$ & $\begin{array}{c}n=47-51 \\
\%(n)\end{array}$ & $\begin{array}{c}n=5262-5713 \\
\%(n)\end{array}$ \\
\hline \multicolumn{6}{|l|}{ Sexual abuse } \\
\hline Any sexual abuse & $82.4(14) *$ & $63.6(7)$ & $47.4(9)$ & $63.8(30)^{* * *}$ & 20.5 (1079) \\
\hline Penetrative sexual abuse & $47.4(9)$ & $63.6(7)$ & $20.0(4)^{*}$ & $39.2(20)^{* * *}$ & 5.9 (329) \\
\hline \multicolumn{6}{|l|}{ Self-injury } \\
\hline Nonsuicidal self-injury & $52.6(10)$ & $41.7(5)$ & $25.0(5)$ & $39.2(29)^{* * *}$ & $17.6(1004)$ \\
\hline Sex as self-injury & $52.6(10)^{* *}$ & $16.7(2)$ & $10.0(2)^{*}$ & $27.5(14)^{* * *}$ & $1.9(110)$ \\
\hline Sexual orientation & & & & & \\
\hline Heterosexual orientation & $42.1(8)^{*}$ & $50.0(6)$ & $85.0(17)^{* *}$ & $60.8(31)^{* * *}$ & 87.4 (4995) \\
\hline \multicolumn{6}{|l|}{ Alcohol/drug abuse } \\
\hline Alcohol binge drinking & $57.9(11)$ & $66.7(8)$ & $75.0(15)$ & $66.7(34)^{* *}$ & $49.2(2811)$ \\
\hline Drug abuse ever & $57.9(11)$ & $66.7(8)$ & $52.6(10)$ & $58.0(29)^{* * *}$ & $22.1(1251)$ \\
\hline Trauma Symptoms Checklist & Mean (SD) & Mean (SD) & Mean (SD) & Mean (SD) & Mean (SD) \\
\hline Anxiety & $8.7(4.6)$ & $9.0(7.4)$ & $6.1(6.4)$ & $7.8(6.1))^{* * *}$ & $4.7(4.0)$ \\
\hline Depression & $10.2(6.5)$ & $8.8(6.9)$ & $6.8(7.6)$ & $8.6(7.0)^{* * *}$ & $5.1(4.5)$ \\
\hline Anger & $8.1(4.7)$ & $7.8(8.4)$ & $8.7(7.5)$ & $8.2(6.7)^{* * *}$ & $4.1(4.0)$ \\
\hline Post-traumatic stress & $13.1(6.3)$ & $9.6(8.0)$ & $9.1(7.2)$ & $10.8(7.2)^{* * *}$ & $6.2(5.1)$ \\
\hline Dissociation & $11.4(6.4)$ & $9.6(8.0)$ & $8.8(7.7)$ & $10.0(7.2)^{* * *}$ & $6.0(4.9)$ \\
\hline Sexual concerns & $6.5(3.6)$ & $5.8(5.7)$ & $5.3(5.2)$ & $5.9(4.7)^{* * *}$ & $2.2(2.5)$ \\
\hline Critical items & $5.8(4.0)$ & $6.4(6.8)$ & $4.2(5.8)$ & $5.3(5.5)^{* * *}$ & $1.7(2.5)$ \\
\hline
\end{tabular}

Note. ${ }^{*} p \leq .05 * * p \leq .01 * * * p \leq .001$ 